\title{
Mild hyperbaric oxygen: mechanisms and effects
}

\author{
Akihiko Ishihara ${ }^{1} \mathbb{B}$ \\ Received: 10 September 2018 / Accepted: 15 April 2019 / Published online: 6 May 2019 \\ (c) The Physiological Society of Japan and Springer Japan KK, part of Springer Nature 2019
}

\begin{abstract}
Adequate oxygen supply by exposure to mild hyperbaric oxygen at appropriately high atmospheric pressure (1266-1317 hPa) and increased oxygen concentration (35-40\% oxygen) has a possibility of improving the oxidative metabolism in cells and tissues without barotrauma and excessive production of reactive oxygen species. Therefore, metabolic syndrome and lifestyle-related diseases, including type 2 diabetes and hypertension, in rats were inhibited and/or improved by exposure to mild hyperbaric oxygen. It accelerated the growth-induced increase in oxidative capacity of the skeletal muscle in rats and inhibited the age-related decrease in oxidative capacity of the skeletal muscle in mice. A decrease in dopaminergic neurons in the substantia nigra of mice with Parkinson's disease was inhibited by exposure to mild hyperbaric oxygen. This review describes the beneficial effects of exposure to mild hyperbaric oxygen on some metabolic diseases and their perspectives.
\end{abstract}

Keywords Dissolved oxygen $\cdot$ Mild hyperbaric oxygen $\cdot$ Oxidative metabolism

\section{Introduction}

Oxygen is essential for energy production in most cells and is carried by red blood cells that flow in blood vessels. The oxygen bound to hemoglobin in red blood cells is referred to as the 'oxygen bound to hemoglobin.' The oxygen dissolved in blood plasma is referred to as the 'dissolved oxygen.' Although the quantity of dissolved oxygen is less than that of oxygen bound to hemoglobin, it can flow to peripheral cells, especially those in the brain, heart, and eyes, even if capillaries are very narrow, since it is dissolved directly in blood plasma (Fig. 1a).

Enhanced atmospheric pressure and/or increased oxygen concentration can increase the oxygen content, especially the dissolved oxygen content in blood plasma [1,2] (Fig. 1b). Exposure to mild hyperbaric oxygen at $1266-1317 \mathrm{hPa}$ with $35-40 \%$ oxygen inhibited metabolic syndrome [3] and lifestyle-related diseases, including type 2 diabetes [4] and hypertension [5], in experimental animals since it improved oxidative metabolism, which was lower than that in controls [6].

Akihiko Ishihara

ishihara.akihiko.8s@kyoto-u.ac.jp

1 Laboratory of Cell Biology and Life Science, Graduate School of Human and Environmental Studies, Kyoto

University, Sakyo-ku, Kyoto 606-8501, Japan
However, side effects associated with enhanced atmospheric pressure and/or increased oxygen concentration, including barotrauma and excessive production of reactive oxygen species in tissues and organs, are thought to occur. Hyperbaric oxygen therapy at 2026-3039 hPa with $100 \%$ oxygen for medical treatment is associated with the risk of inducing myopia and cataracts [7-9]. A previous study [7] reported that exposure to hyperbaric oxygen at $2534 \mathrm{hPa}$ with $100 \%$ oxygen for $2-2.5 \mathrm{~h}$, twice a week, up to 100 sessions, induces cataracts in guinea pigs. Similarly, myopia and cataracts developed in human lenses after exposure to prolonged hyperbaric conditions of 2026-2534 hPa with $100 \%$ oxygen for $90 \mathrm{~min}$, once a day, from 150 to 850 sessions [8]; however, it was rarely seen to occur after only 48 sessions of hyperbaric oxygen conditions at $2534 \mathrm{hPa}$ for 90 min [9]. Hyperbaric oxygen therapy increases the number of invasive inflammatory cells in mice [10] and causes excessive production of reactive oxygen species in rats [11, 12], rabbits [13], and humans [14]. Excessive production of reactive oxygen species plays a key role in the pathogenesis of many diseases and their complications; generation of free radicals and increased levels of oxidative stress are associated with atherosclerosis, cataracts, retinopathy, myocardial infarction, hypertension, diabetes, renal failure, and uremia [15-17]. In addition, regardless of pressure, oxygen treatments involving $>40 \%$ oxygen have shown adverse effects, e.g., damage of erythrocytes due to reactive oxygen species 


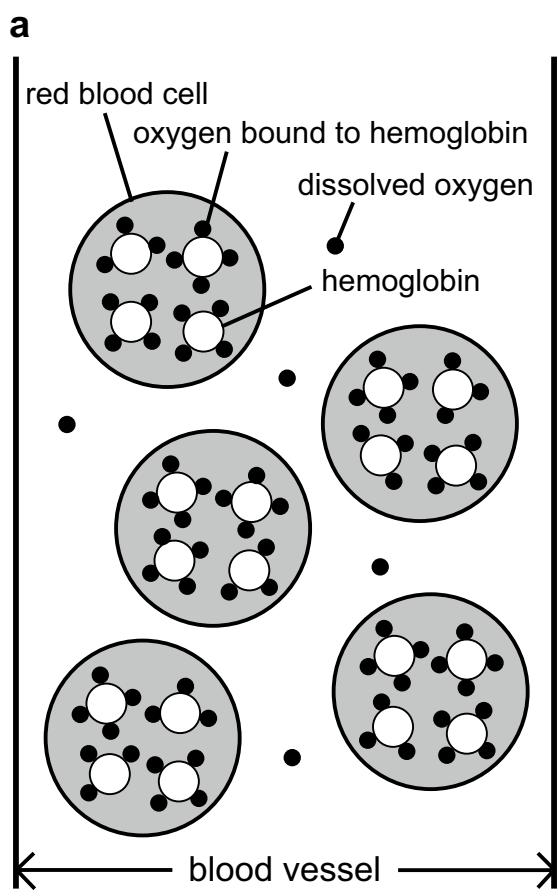

Fig. 1 Schematic diagram depicting the distribution of oxygen bound to hemoglobin and dissolved oxygen in blood vessels under normobaric (a) and mild hyperbaric oxygen (b) conditions. Abundant hemoglobin is distributed in red blood cells, and up to four oxygen molecules can bind to one hemoglobin (oxygen bound to hemoglobin). The other kind of oxygen is dissolved in blood plasma (dissolved oxygen). The quantity of dissolved oxygen is less than that of oxygen

and reduced quantity of oxygen bound to hemoglobin in rats [18].

Exposure to mild hyperbaric oxygen at a low oxygen concentration (35-40\% oxygen) does not result in enhanced levels of oxidative stress in rats [5, 19] and humans [20]. Based on previous findings from experimental animal and human clinical studies, the effects of exposure to mild hyperbaric oxygen at $1266-1317 \mathrm{hPa}$ with $35-40 \%$ oxygen are summarized in Table 1. It is noteworthy that these findings were obtained in the first step of exposure to mild hyperbaric oxygen. Therefore, it is expected to define a suitable recommendation regarding a generally applicable protocol for exposure to mild hyperbaric oxygen in the subsequent step. This review describes the beneficial effects of exposure to mild hyperbaric oxygen on some metabolic diseases and related perspectives.

\section{Metabolic syndrome}

Metabolic syndrome, linked to chronic physical inactivity and consumption of a high-fat and high-calorie diet, is characterized by obesity, high blood pressure, and increased blood glucose, low density b

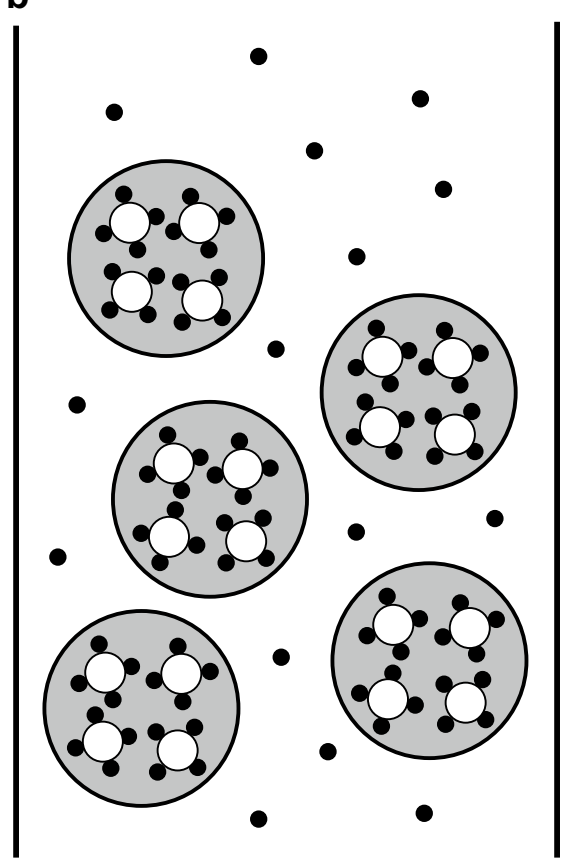

bound to hemoglobin. Enhanced atmospheric pressure and/or oxygen concentration can increase oxygen in the body, especially dissolved oxygen in blood plasma. In addition, dissolved oxygen is able to flow to the peripheral cells, especially those in the brain, heart, and eyes, even if capillaries are very narrow, since it is dissolved directly in blood plasma

lipoprotein-cholesterol, and triglyceride levels [21, 22]. Experimental animals with metabolic syndrome have a nonsense mutation in the leptin receptor [23, 24]. Rats with metabolic syndrome have a low oxidative capacity in the skeletal muscle compared to normal rats $[6,25]$. Reduced oxidative capacity in the skeletal muscle is suggested to impair glucose metabolism and increase the risk of development of metabolic syndrome [6, 21, 22, 25]. Rats with metabolic syndrome exposed to mild hyperbaric oxygen had lower blood pressure, blood glucose, total cholesterol, triglyceride, and insulin levels, but higher adiponectin levels than those not exposed to mild hyperbaric oxygen [3]. In addition, rats with metabolic syndrome exposed to mild hyperbaric oxygen had high oxidative capacity and increased levels of peroxisome proliferatoractivated receptor $\gamma$ coactivator-1 $\alpha(P g c-1 \alpha)$ mRNA, which plays an important role in oxidative metabolism by regulating mitochondrial biogenesis in the skeletal muscle $[26,27]$.

Exposure to mild hyperbaric oxygen is thus considered to inhibit the growth-related increase in blood glucose levels and decrease the muscle oxidative capacity of rats with metabolic syndrome owing to the improved oxidative metabolism [3]. 
Table 1 Effects of exposure to mild hyperbaric oxygen reported in previous studies

\begin{tabular}{|c|c|c|c|}
\hline & Species & Effects & References \\
\hline Metabolic syndrome & SHR/NDmcr-cp rat & Inhibition of metabolic syndrome & {$[3]$} \\
\hline \multirow[t]{3}{*}{ Type 2 diabetes } & GK rat & Inhibition of type 2 diabetes & {$[4,36,37]$} \\
\hline & OLETF rat & Inhibition of type 2 diabetes & {$[38]$} \\
\hline & GK rat & Improvement of type 2 diabetes & [39] \\
\hline Diabetes-induced cataracts & Repeated inbreeding of diabetic mouse & Inhibition of cataracts & {$[46]$} \\
\hline Hypertension & SHR & Inhibition of hypertension & {$[5]$} \\
\hline Arthritis & Collagen-induced DA rat & Inhibition of arthritis & [19] \\
\hline Parkinson's disease & MTPT-injected C57BL/6JJmsSlc mouse & Inhibition of decrease in dopaminergic neuron & {$[86]$} \\
\hline \multirow[t]{2}{*}{ Pigmentation } & Male subject irradiated with UVB & Melanin pigmentation turns light & {$[62]$} \\
\hline & Female subject & Senile spot size becomes small & {$[62]$} \\
\hline Proliferation & Aged hairless (Hos, HR-1) mouse & Improvement of proliferative activity of epidermal basal cell & {$[60]$} \\
\hline Metabolism & Human & $\begin{array}{l}\text { Decrease in } \mathrm{SpO} 2 \text {, increase in resting HR and energy } \\
\text { expenditure }\end{array}$ & {$[20]$} \\
\hline \multirow[t]{3}{*}{ Skeletal muscle fiber } & Wistar rat & Increase in oxidative capacity & {$[63,64]$} \\
\hline & Wistar rat & Inhibition of atrophy & [83] \\
\hline & Aged ICR mouse & Improvement of oxidative capacity & [69] \\
\hline \multirow[t]{2}{*}{ Spinal motoneuron } & Wistar rat & Increase in oxidative capacity & {$[63,64]$} \\
\hline & GK rat & Improvement of oxidative capacity & [44] \\
\hline Infertility & Woman with intractable infertility & Improvement of the outcome of in vitro fertilization & [96] \\
\hline
\end{tabular}

SHR spontaneously hypertensive rat, GK Goto-Kakizaki, OLETF Otsuka Long-Evans Tokushima Fatty, DA dark Agouti, UVB ultraviolet B, ICR Institute of Cancer Research, MPTP 1-methyl-4-phenyl-1,2,3,6-tetrahydropyridine hydrochloride, $S p O 2$ peripheral oxygen saturation, $H R$ heart rate

\section{Type 2 diabetes}

In general, blood glucose, hemoglobin A1c (HbA1c), and triglyceride levels are higher in patients with diabetes than in healthy lean people. Hyperglycemia worsens vascular disorders including a stroke, myocardial infarction, retinopathy, nephropathy, and peripheral neuropathy. Patients with type 2 diabetes have decreased oxidative capacity in the skeletal muscle, similar to those with metabolic syndrome [28]. Decreased oxidative capacity in the skeletal muscle of patients with diabetes is suggested to be related to insulin resistance and impaired glucose metabolism. Both nonobese and obese rats with diabetes, which were developed as Goto-Kakizaki [29, 30] and Otsuka Long-Evans Tokushima Fatty [31] models, respectively, have lower oxidative capacity in the skeletal muscle than that of normal rats [32-34]. Zucker diabetic fatty rats show similar muscle properties as obese rats with diabetes [35]. Blood glucose, HbA1c, and triglyceride levels were higher in non-obese and obese rats with diabetes than in normal rats [33, 34], and those levels improved by exposure to mild hyperbaric oxygen $[4,36]$. In the skeletal muscle, $P g c-1 \alpha$, myogenin, and myogenic factor 5 mRNA levels and oxidative capacity were higher in rats with diabetes exposed to mild hyperbaric oxygen than in those not exposed to mild hyperbaric oxygen [37, 38].

The growth-related increase in blood glucose levels in rats with type 2 diabetes was inhibited by exposure to mild hyperbaric oxygen [4, 36-38]. The decreased blood glucose levels induced by exposure to mild hyperbaric oxygen in rats with type 2 diabetes were maintained even after these rats were subsequently returned to breeding under normobaric conditions [39]. The increased blood glucose levels of adult rats with type 2 diabetes not exposed to mild hyperbaric oxygen were lowered even if they were exposed to mild hyperbaric oxygen afterward [39]. These results indicate that low blood glucose levels in rats with type 2 diabetes can be maintained by exposure to mild hyperbaric oxygen compared to those not exposed to mild hyperbaric oxygen, both when blood glucose levels are increasing during growth [36-38] and after blood glucose levels are high in adulthood [39].

Exposure to mild hyperbaric oxygen, therefore, seems to prevent the decrease in oxidative capacity of the skeletal muscle of rats with type 2 diabetes, irrespective of their age [36-38]. In addition, exposure to mild hyperbaric oxygen is effective for the inhibition [4, 36-38] as well as improvement [39] of hyperglycemia in rats with type 2 diabetes.

The morphological and histochemical properties of fibers in the skeletal muscle correspond well with those of spinal motoneurons that innervate muscle fibers [40-43]. A previous study [44] had shown decreased oxidative capacity of spinal motoneurons in rats with type 2 diabetes. In addition, this study [44] had examined the effects of exposure to mild hyperbaric oxygen on oxidative capacity 
of spinal motoneurons. The inhibition of growth-related decrease in oxidative capacity of spinal motoneurons by exposure to mild hyperbaric oxygen corresponds well with that observed in muscle fibers innervated by spinal motoneurons, thereby implying that the properties and responses of spinal motoneurons and their innervating muscle fibers are closely related under diabetic, as well as normal conditions [44].

\section{Diabetes-induced cataracts}

Cataracts are characterized by an accumulation of sorbitol, mediated by aldose reductase activity. The polyol pathway is the major contributor to diabetes-induced cataracts, i.e., the denaturation of lens protein, since an increased flux of glucose via this pathway leads to diabetic lesions in the lens, and large quantities of glucose are reduced to sorbitol, which is not metabolized any further [45]. The increased availability of oxygen by exposure to mild hyperbaric oxygen inhibited the growth-related increase in blood glucose levels in rats with type 2 diabetes, thereby delaying cataract formation induced by the accumulation of sorbitol in the lens [46].

\section{Hypertension}

Spontaneously hypertensive rats (SHRs) were developed by repeated inbreeding of normal Wistar-Kyoto rats, which exhibited high blood pressure levels [47]. SHRs exposed to mild hyperbaric oxygen showed lower systolic and diastolic blood pressure levels than those of age-matched SHRs not exposed to mild hyperbaric oxygen [5]. Furthermore, SHRs exposed to mild hyperbaric oxygen had lower oxidative stress and higher antioxidant levels than age-matched SHRs not exposed to mild hyperbaric oxygen [5]. Abnormalities of central neural mechanisms regulating the peripheral sympathetic outflow, i.e., an enhanced sympathetic activation and catecholamine metabolism following neurotransmitter release from nerve endings, have been associated with hypertension [48, 49]. An enhanced sympathetic activation in rats with hypertension is mediated by the overproduction of highly reactive oxygen species, which induces sympathoexcitation and thus hypertension [50,51], whereas exposure to mild hyperbaric oxygen has been suggested to eliminate reactive oxygen species and maintain normal blood pressure levels [5]. An enhancement of oxidative metabolism in cells and tissues increases the carbon dioxide concentration in the surrounding region, which in turn, facilitates blood flow in blood vessels [52, 53].

\section{Arthritis}

Exposure to mild hyperbaric oxygen is effective in decreasing levels of reactive oxygen species overproduced in arthritis [19]. Oxidative stress and C-reactive protein levels are high in rats with arthritis [54], whereas the levels shifted to those in normal rats by exposure to mild hyperbaric oxygen [19]. Arthritic joints are characterized by hypoxia caused by an increased oxygen demand and decreased blood flow triggered by the increased intraarticular pressure [55-57]. Therefore, exposure to mild hyperbaric oxygen is effective in reducing reactive oxygen species levels overproduced during arthritis [19].

\section{Pigmentation and proliferation}

The skin undergoes age-related degenerative changes, including tissue dehydration and transepidermal water loss [58]. Proliferation of epidermal basal cells decreases with age [59]. Exposure to mild hyperbaric oxygen has been reported to accelerate the proliferative activity of epidermal basal cells in aged mouse skin [60]. An adequate oxygen supply from exposure to mild hyperbaric oxygen may accelerate the turnover rate of aged skin by enhancing the proliferative activity of epidermal basal cells. Therefore, the dissolved oxygen, which is increased by exposure to mild hyperbaric oxygen, is considered to diffuse from the dermis to the epidermis through blood microcirculation, thus accelerating proliferation of epidermal basal cells and inhibiting epidermal aging [60].

Suppression of ultraviolet B irradiation-induced pigmentation is due, at least in part, to the reduction in prostaglandin synthesis via the inhibition of cyclooxygenase by indomethacin, and to the induction of annexin or lipocortin by corticosteroids [61]. Exposure to mild hyperbaric oxygen was found to accelerate the fading of ultraviolet $\mathrm{B}$ irradiation-induced melanin pigmentation of the skin [62]. Furthermore, senile spot sizes on faces became smaller after exposure to mild hyperbaric oxygen [62]. Keratinocyte proliferation and epidermal cell regeneration are considered to be activated by enhanced oxidative metabolism induced by exposure to mild hyperbaric oxygen, which may be effective for damage repair in the epidermis.

\section{Adaptation of the neuromuscular system}

Exposure to mild hyperbaric oxygen facilitates oxidative metabolism, particularly in pathways such as the mitochondrial tricarboxylic acid cycle, thus enhancing the oxidative 
capacity of skeletal muscle fibers and the spinal motoneurons innervating them $[63,64]$. Growing rats exposed to mild hyperbaric oxygen exhibited greater voluntary running activities compared to those maintained under normobaric conditions (without exposure to mild hyperbaric oxygen); the oxidative capacity of muscle fibers and the innervating spinal motoneurons in rats increased after exposure to mild hyperbaric oxygen [64].

Reduction in skeletal muscle mass is one of the most striking features of the aging process [65]. Atrophy and reduced oxidative capacity of the skeletal muscle have been observed with age $[66,67]$. Muscle atrophy in aged rats is associated with reduced activity levels of certain enzymes involved in oxidative metabolism [68]. An agerelated decrease in oxidative capacity of the skeletal muscle in mice was reported to be reversed by exposure to mild hyperbaric oxygen [69] as much as by exercise in aged rats [70]. Exposure to mild hyperbaric oxygen has an advantage over exercise since it can increase the dissolved oxygen content owing to the enhanced atmospheric pressure and/ or increased oxygen concentration, which does not occur in exercise. Therefore, it is concluded that exposure to mild hyperbaric oxygen reduces the age-related decrease in oxidative capacity of the skeletal muscle due to the improvement in oxidative metabolism [69].

Chronic inactivity, as in hind limb unloading and microgravity exposure, induces atrophy and degenerative changes in the skeletal muscle and its fibers [71-75], as well as in spinal motoneurons that innervate the muscle fibers [76-82]. Muscle atrophy and decreased oxidative capacity were shown to be unaffected by either pre- or post-conditioning with exposure to mild hyperbaric oxygen [83]. In contrast, the degenerative changes were almost restored to normal levels after reloading, when pre- and post-conditionings with exposure to mild hyperbaric oxygen were combined [83]. Only a combination of pre- and post-conditionings is considered to activate the signaling cascades required for the recovery from atrophy and decreased oxidative capacity of the skeletal muscle.

\section{Parkinson's disease}

Parkinson's disease is a progressive neurodegenerative disorder in the elderly that is characterized by typical motor symptoms such as resting tremors, rigidity, bradykinesia, and gait disturbances [84]. Parkinson's disease results from the progressive decrease in dopaminergic neurons in the substantia nigra [85]. Exposure to mild hyperbaric oxygen was shown to inhibit the decrease in dopaminergic neurons in the substantia nigra of a neurotoxic experimental animal with Parkinson's disease [86]. The number of times the feet of the mouse slid off the stick in a balance beam test was fewer in mice with Parkinson's disease exposed to mild hyperbaric oxygen than in those not exposed to mild hyperbaric oxygen [86]. PGC- $1 \alpha$, a transcriptional co-activator, may be one of the factors that contribute to the improvement in oxidative metabolism of dopaminergic neurons in Parkinson's disease [87], since oxidative metabolism, mitochondrial biogenesis, oxidative stress, and gene expression are regulated by PGC- $1 \alpha[88,89]$.

It is concluded that exposure to mild hyperbaric oxygen activates oxidative metabolism in the dopaminergic neurons in the substantia nigra and inhibits the reduction in dopaminergic neurons, thereby resulting in the inhibition of Parkinson's disease [86].

\section{Infertility}

Hyperbaric oxygen therapy, an established medical treatment usually conducted under conditions of 2026-3039 hPa with $100 \%$ oxygen, has been investigated for improving female [90-93] and male [94, 95] infertility. However, several side effects, including barotrauma and excessive production of reactive oxygen species, associated with hyperbaric oxygen therapy, have been reported [7-12, 14]. Low metabolism in the uterus and ovaries may be a factor responsible for infertility since the former reduces the ability of fertilized eggs to remain in the uterus. Exposure to mild hyperbaric oxygen has been suggested to enhance oxygen supply to cells and tissues, thus improving oxidative metabolism, without barotrauma and excessive production of reactive oxygen species. In a recent study [96], 37 women with intractable infertility, who had previously received over 5 embryo transfers with a low clinical pregnancy rate $(4.9 \%)$ and without birth, were exposed to mild hyperbaric oxygen before receiving any further embryo transfer. As a result, 13 women achieved clinical pregnancy with a rate of $13.8 \%$; 5 women gave birth after in vitro fertilization treatment. Two women achieved natural conception and gave birth. However, 1 woman had an extra-uterine pregnancy, and 5 women had miscarriages.

\section{Perspectives on exposure to mild hyperbaric oxygen}

Exposure to mild hyperbaric oxygen is effective for elderly people, those with physical disability, as well as injured athletes, since no special movement needs to be performed under mild hyperbaric oxygen conditions. In future, exposure to mild hyperbaric oxygen may be investigated for: (1) prevention and improvement of dementia, (2) improvement of functional imbalances of autonomic (sympathetic and parasympathetic) nerves, e.g., menopausal disorders and emotional instability, (3) maintenance and improvement of 
immunity, health, and physical fitness, and (4) early recovery from an injury. Further studies are required to solve these problems and define a useful protocol for exposure to mild hyperbaric oxygen.

\section{Compliance with ethical standards}

Ethical approval This article does not contain any studies with animals or human participants performed by the author.

\section{References}

1. Tibbles PM, Edelsberg JS (1996) Hyperbaric-oxygen therapy. N Engl J Med 334:1642-1648

2. Leach RM, Rees PJ, Wilmshurst P (1998) Hyperbaric oxygen therapy. BMJ 317:1140-1143

3. Takemura A, Ishihara A (2017) Mild hyperbaric oxygen inhibits growth-related decrease in muscle oxidative capacity of rats with metabolic syndrome. J Atheroscler Thromb 24:26-38

4. Yasuda K, Aoki N, Adachi T, Tsujimoto G, Gu N, Matsunaga T, Kikuchi N, Tsuda K, Ishihara A (2006) Hyperbaric exposure with high oxygen concentration inhibits growth-associated increase in the glucose level of diabetic Goto-Kakizaki rats. Diabetes Obes Metab 8:714-715

5. Nagatomo F, Fujino H, Takeda I, Ishihara A (2010) Effects of hyperbaric oxygenation on blood pressure levels of spontaneously hypertensive rats. Clin Exp Hypertens 32:193-197

6. Nagatomo F, Gu N, Fujino H, Takeda I, Tsuda K, Ishihara A (2009) Skeletal muscle characteristics of rats with obesity, diabetes, hypertension, and hyperlipidemia. J Atheroscler Thromb 16:576-585

7. Giblin FJ, Padgaonkar VA, Leverenz VR, Lin LR, Lou MF, Unakar NJ, Dang L, Dickerson JE Jr, Reddy VN (1995) Nuclear light scattering, disulfide formation and membrane damage in lenses of older guinea pigs treated with hyperbaric oxygen. Exp Eye Res 60:219-235

8. Palmquist BM, Philipson B, Barr PO (1984) Nuclear cataract and myopia during hyperbaric oxygen therapy. $\mathrm{Br} \mathrm{J}$ Ophthalmol 68:113-117

9. Gesell LB, Trott A (2007) De novo cataract development following a standard course of hyperbaric oxygen therapy. Undersea Hyperb Med 34:389-392

10. Folz RJ, Abushamaa AM, Suliman HB (1999) Extracellular superoxide dismutase in the airways of transgenic mice reduces inflammation and attenuates lung toxicity following hyperoxia. J Clin Invest 103:1055-1066

11. Oter S, Korkmaz A, Topal T, Ozcan O, Sadir S, Ozler M, Ogur R, Bilgic H (2005) Correlation between hyperbaric oxygen exposure pressures and oxidative parameters in rat lung, brain, and erythrocytes. Clin Biochem 38:706-711

12. Oter S, Topal T, Sadir S, Ozler M, Uysal B, Ay H, Yaren H, Korhmaz A, Akin A (2007) Oxidative stress levels in rats following exposure to oxygen at $3 \mathrm{~atm}$ for 0-120 min. Aviat Space Environ Med 78:1108-1113

13. Padgaonkar VA, Leverenz VR, Fowler KE, Reddy VN, Giblin FJ (2000) The effects of hyperbaric oxygen on the crystallins of cultured rabbit lenses: a possible catalytic role for copper. Exp Eye Res 71:371-383
14. Narkowicz CK, Vial JH, McCartney PW (1993) Hyperbaric oxygen therapy increases free radical levels in the blood of humans. Free Radic Res Commun 19:71-80

15. Maier CM, Chan PH (2002) Role of superoxide dismutases in oxidative damage and neurodegenerative disorders. Neuroscientist $8: 323-334$

16. Griendling KK, FitzGerald GA (2003) Oxidative stress and cardiovascular injury: part I: basic mechanisms and in vivo monitoring of ROS. Circulation 108:1912-1916

17. Dalle-Donne I, Rossi R, Colombo R, Giustarini D, Milzani A (2006) Biomarkers of oxidative damage in human disease. Clin Chem 52:601-623

18. Nagatomo F, Fujino H, Kondo H, Ishihara A (2012) Oxygen concentration-dependent oxidative stress levels in rats. Oxid Med Cell Longev https://doi.org/10.1155/2012/381763

19. Nagatomo F, Gu N, Fujino H, Okiura T, Morimatsu F, Takeda I, Ishihara A (2010) Effects of exposure to hyperbaric oxygen on oxidative stress in rats with type II collagen-induced arthritis. Clin Exp Med 10:7-13

20. Ishihara A, Nagatomo F, Fujino H, Kondo H (2014) Exposure to mild hyperbaric oxygen increases blood flow and resting energy expenditure but not oxidative stress. J Sci Res Rep 3:1886-1896

21. Nagatomo F, Fujino H, Kondo H, Takeda I, Tsuda K, Ishihara A (2012) High-fat diet-induced reduction of PGC- $1 \alpha$ mRNA levels and oxidative capacity in the soleus muscle of rats with metabolic syndrome. Nutr Res 32:144-151

22. Nagatomo F, Fujino H, Kondo H, Kouzaki K, Gu N, Takeda I, Tsuda K, Ishihara A (2012) The effects of running exercise on oxidative capacity and PGC- $1 \alpha$ mRNA levels in the soleus muscle of rats with metabolic syndrome. J Physiol Sci 62:105-114

23. Koletsky S (1973) Obese spontaneously hypertensive rats-a model for study of atherosclerosis. Exp Mol Pathol 19:53-60

24. Koletsky S (1975) Pathologic findings and laboratory data in a new strain of obese hypertensive rats. Am J Pathol 80:129-142

25. Nagatomo F, Fujino H, Kondo H, Gu N, Takeda I, Ishioka N, Tsuda K, Ishihara A (2011) PGC- $1 \alpha$ mRNA level and oxidative capacity of the plantaris muscle in rats with metabolic syndrome, hypertension, and type 2 diabetes. Acta Histochem Cytochem 44:73-80

26. Miura S, Kai Y, Ono M, Ezaki O (2003) Overexpression of peroxisome proliferator-activated receptor $\gamma$ coactivator- $1 \alpha$ downregulates GLUT4 mRNA in skeletal muscles. J Biol Chem 278:31385-31390

27. Mortensen $\mathrm{OH}$, Frandsen L, Schjerling P, Nishimura E, Grunnet N (2006) PGC-1 $\alpha$ and PGC- $1 \beta$ have both similar and distinct effects on myofiber switching towards an oxidative phenotype. Am J Physiol Endocrinol Metab 291:E807-E816

28. Ishihara A, Nagatomo F, Fujino H, Kondo H, Tsuda K (2012) Lifestyle-related disease and skeletal muscle. J Phys Fit Sports Med 1:17-27

29. Goto Y, Kakizaki M, Masaki N (1975) Spontaneous diabetes produced by selective breeding of normal Wistar rats. Proc Jpn Acad 51:80-85

30. Goto Y, Kakizaki M, Masaki N (1976) Production of spontaneous diabetic rats by repetition of selective breeding. Tohoku J Exp Med 119:85-90

31. Kawano K, Hirashima T, Mori S, Saitoh Y, Kurosumi M, Natori $\mathrm{T}$ (1992) Spontaneous long-term hyperglycemic rat with diabetic complications. Otsuka Long-Evans Tokushima Fatty (OLETF) strain. Diabetes 41:1422-1428

32. Yasuda K, Ishihara A, Adachi T, Shihara N, Seino Y, Tsuda K (2001) Growth-related changes in skeletal muscle fiber type and insulin resistance in diabetic Otsuka Long-Evans Tokushima Fatty rats. Acta Histochem Cytochem 34:371-382

33. Yasuda K, Nishikawa W, Iwanaka N, Nakamura E, Seino Y, Tsuda K, Ishihara A (2002) Abnormality in fibre type distribution of 
soleus and plantaris muscles in non-obese diabetic Goto-Kakizaki rats. Clin Exp Pharmacol Physiol 29:1001-1008

34. Yasuda K, Adachi T, Kikuchi N, Tsujimoto G, Aoki N, Tsuda K, Ishihara A (2006) Effects of running exercise on fibre-type distribution of soleus and plantaris muscles in diabetic Otsuka LongEvans Tokushima fatty rats. Diabetes Obes Metab 8:311-321

35. Adachi T, Kikuchi N, Yasuda K, Anahara R, Gu N, Matsunaga T, Yamamura T, Mori C, Tsujimoto G, Tsuda K, Ishihara A (2007) Fibre type distribution and gene expression levels of both succinate dehydrogenase and peroxisome proliferator-activated receptor- $\gamma$ coactivator- $1 \alpha$ of fibres in the soleus muscle of Zucker diabetic fatty rats. Exp Physiol 92:449-455

36. Yasuda K, Adachi T, Gu N, Matsumoto A, Matsunaga T, Tsujimoto G, Tsuda K, Ishihara A (2007) Effects of hyperbaric exposure with high oxygen concentration on glucose and insulin levels and skeletal muscle-fiber properties in diabetic rats. Muscle Nerve 35:337-343

37. Matsumoto A, Nagatomo F, Yasuda K, Tsuda K, Ishihara A (2007) Hyperbaric exposure with high oxygen concentration improves altered fiber types in the plantaris muscle of diabetic Goto-Kakizaki rats. J Physiol Sci 57:133-136

38. Nagatomo F, Takemura A, Roy RR, Fujino H, Kondo H, Ishihara A (2018) Mild hyperbaric oxygen inhibits the growth-related decline in skeletal muscle oxidative capacity and prevents hyperglycemia in rats with type 2 diabetes. J Diabetes 10:753-763

39. Gu N, Nagatomo F, Fujino H, Takeda I, Tsuda K, Ishihara A (2010) Hyperbaric oxygen exposure improves blood glucose level and muscle oxidative capacity in rats with type 2 diabetes. Diabetes Technol Ther 12:125-133

40. Ishihara A, Roy RR, Edgerton VR (1995) Succinate dehydrogenase activity and soma size of motoneurons innervating different portions of the rat tibialis anterior. Neuroscience 68:813-822

41. Ishihara A, Hori A, Roy RR, Oishi Y, Talmadge RJ, Ohira Y, Kobayashi S, Edgerton VR (1997) Perineal muscles and their innervation: metabolic and functional significance of the motor unit. Acta Anat 159:156-166

42. Ishihara A, Itoh K, Itoh M, Hirofuji C (2000) Effect of hypobaric hypoxia on rat soleus muscle fibers and their innervating motoneurons: a review. Jpn J Physiol 50:561-568

43. Nakatani T, Nakashima T, Kita T, Ishihara A (2003) Cell size and oxidative enzyme activity of type-identified fibers in rat hindlimb muscles: a review. Acta Histochem Cytochem 36:105-114

44. Takemura A, Ishihara A (2016) Mild hyperbaric oxygen improves decreased oxidative capacity of spinal motoneurons innervating the soleus muscle of rats with type 2 diabetes. Neurochem Res 41:2336-2344

45. Chung SSM, Ho ECM, Lam KSL, Chung SK (2003) Contribution of polyol pathway to diabetes-induced oxidative stress. J Am Soc Nephrol 14(Suppl 3):233-236

46. Nagatomo F, Roy RR, Takahashi H, Edgerton VR, Ishihara A (2011) Effect of exposure to hyperbaric oxygen on diabetesinduced cataracts in mice. J Diabetes 3:301-308

47. Okamoto K, Aoki K (1963) Development of a strain of spontaneously hypertensive rats. Jpn Circ J 27:282-293

48. Patel KP, Kline RL, Mercer PF (1981) Noradrenergic mechanisms in the brain and peripheral organs of normotensive and spontaneously hypertensive rats at various ages. Hypertension 3:682-690

49. Grassi G (1998) Role of the sympathetic nervous system in human hypertension. J Hypertens 16:1979-1987

50. Kishi T, Hirooka Y, Kimura Y, Ito K, Shimokawa H, Takeshita A (2004) Increased reactive oxygen species in rostral ventrolateral medulla contribute to neural mechanisms of hypertension in stroke-prone spontaneously hypertensive rats. Circulation 109:2357-2362

51. Lindley TE, Doobay MF, Sharma RV, Davisson RI (2004) Superoxide is involved in the central nervous system activation and sympathoexcitation of myocardial infarction-induced heart failure. Circ Res 94:402-409

52. Matsumoto T, Tanaka M, Ikeji T, Maeshige N, Sakai Y, Akisue T, Kondo H, Ishihara A, Fujino H (2019) Application of transcutaneous carbon dioxide improves capillary regression of skeletal muscle in hyperglycemia. J Physiol Sci 69: 317-326

53. Matsumoto T, Tanaka M, Nakanishi R, Takuwa M, Hirabayashi T, Ono K, Ikeji T, Maeshige N, Sakai Y, Akisue T, Kondo K, Ishihara A, Fujino H (2019) Transcutaneous carbon dioxide attenuates impaired oxidative capacity in skeletal muscle in hyperglycemia. Gen Physiol Biophys (accepted)

54. Okiura T, Nagatomo F, Gu N, Taguchi Y, Morimatsu F, Ishihara A (2008) Bone density of the femur and fiber cross-sectional area and oxidative enzyme activity of the tibialis anterior muscle in type II collagen-induced arthritic mice. J Physiol Sci 58:221-227

55. Woodruff T, Blake DR, Freeman J, Andrews FJ, Salt P, Lunec J (1986) Is chronic synovitis an example of reperfusion injury? Ann Rheum Dis 45:608-611

56. Cross CE, Halliwell B, Borish ET, Pryor WA, Ames BN, Saul RL, McCord JM, Harman D (1987) Oxygen radicals and human disease. Ann Intern Med 107:526-545

57. Blake DR, Merry P, Unsworth J, Kidd BL, Outhwaite JM, Ballard R, Morris CJ, Gray L, Lunec J (1989) Hypoxic-reperfusion injury in the inflamed human joint. Lancet 11:289-293

58. Wilhelm KP, Cua AB, Maibach HI (1991) Skin aging: effect on transepidermal water loss, stratum corneum hydration, skin surface $\mathrm{pH}$, and casual sebum content. Arch Dermatol 127:1806-1809

59. Grove GL, Kligman AM (1983) Age-associated changes in human epidermal cell renewal. J Gerontol 38:137-142

60. Nishizaka T, Nomura T, Higuchi K, Takemura A, Ishihara A (2018) Mild hyperbaric oxygen activates the proliferation of epidermal basal cells in aged mice. J Dermatol 45:1141-1144

61. Flower RJ (1986) Background and discovery of lipocortins. Agents Actions 17:255-262

62. Nishizaka T, Nomura T, Sano T, Higuchi K, Nagatomo F, Ishihara A (2011) Hyperbaric oxygen improves UVB irradiation-induced melanin pigmentation and diminishes senile spot size. Skin Res Tech 17:332-338

63. Ishihara A, Kawano F, Okiura T, Morimatsu F, Ohira Y (2005) Hyperbaric exposure with high oxygen concentration enhances oxidative capacity of neuromuscular units. Neurosci Res 52:146-152

64. Matsumoto A, Okiura T, Morimatsu F, Ohira Y, Ishihara A (2007) Effects of hyperbaric exposure with high oxygen concentration on the physical activity of developing rats. Dev Neurosci 29:452-459

65. Schiaffino S, Dyar KA, Ciciliot S, Blaauw B, Sandri M (2013) Mechanisms regulating skeletal muscle growth and atrophy. FEBS J 280:4294-4314

66. Ishihara A, Naitoh $\mathrm{H}$, Katsuta $\mathrm{S}$ (1987) Effects of ageing on the total number of muscle fibers and motoneurons of the tibialis anterior muscles in the rat. Brain Res 435:355-358

67. Ishihara A, Araki H (1988) Effects of age on the number and histochemical properties of muscle fibers and motoneurons in the rat extensor digitorum longus muscle. Mech Ageing Dev 45:213-221

68. Hirofuji C, Ishihara A, Roy RR, Itoh K, Itoh M, Edgerton VR, Katsuta S (2000) SDH activity and cell size of tibialis anterior motoneurons and muscle fibers in SAMP6. Neuroreport $11: 823-828$

69. Nishizaka T, Nagatomo F, Fujino H, Nomura T, Sano T, Higuchi K, Takeda I, Ishihara A (2010) Hyperbaric oxygen exposure reduces age-related decrease in oxidative capacity of the tibialis anterior muscle in mice. Enzyme Res https://doi. org/10.4061/2010/824763

70. Ishihara A, Taguchi S (1993) Effect of exercise on age-related muscle atrophy. Neurobiol Aging 14:331-335 
71. Ishihara A, Oishi Y, Roy RR, Edgerton VR (1997) Influence of two weeks of non-weight bearing on rat soleus motoneurons and muscle fibers. Aviat Space Environ Med 68:421-425

72. Ishihara A, Kawano F, Ishioka N, Oishi H, Higashibata A, Shimazu T, Ohira Y (2004) Effects of running exercise during recovery from hindlimb unloading on soleus muscle fibers and their spinal motoneurons in rats. Neurosci Res 48:119-127

73. Ishihara A, Fujino H, Nagatomo F, Takeda I, Ohira Y (2008) Gene expression levels of heat shock proteins in the soleus and plantaris muscles of rats after hindlimb suspension or spaceflight. J Physiol Sci 58:413-417

74. Nagatomo F, Fujino H, Kondo H, Suzuki H, Kouzaki M, Takeda I, Ishihara A (2011) PGC-1 $\alpha$ and FOXO1 mRNA levels and fiber characteristics of the soleus and plantaris muscles in rats after hindlimb unloading. Histol Histopathol 26:1545-1553

75. Ishihara A, Nagatomo F, Terada M, Fujino H, Kondo H, Ishioka $\mathrm{N}$ (2015) Effects of microgravity on the mouse triceps brachii muscle. Muscle Nerve 52:63-68

76. Ishihara A, Ohira Y, Roy RR, Nagaoka S, Sekiguchi C, Hinds WE, Edgerton VR (1996) Influence of spaceflight on succinate dehydrogenase activity and soma size of rat ventral horn neurons. Acta Anat 157:303-308

77. Ishihara A, Ohira Y, Roy RR, Nagaoka S, Sekiguchi C, Hinds WE, Edgerton VR (1997) Effects of 14 days of spaceflight and nine days of recovery on cell body size and succinate dehydrogenase activity of rat dorsal root ganglion neurons. Neuroscience 81:275-279

78. Ishihara A, Ohira Y, Roy RR, Nagaoka S, Sekiguchi C, Hinds WE, Edgerton VR (2000) Comparison of the response of motoneurons innervating perineal and hind limb muscles to spaceflight and recovery. Muscle Nerve 23:753-762

79. Ishihara A, Ohira Y, Roy RR, Nagaoka S, Sekiguchi C, Hinds WE, Edgerton VR (2002) Succinate dehydrogenase activity in rat dorsolateral ventral horn motoneurons at L6 after spaceflight and recovery. J Gravit Physiol 9:39-48

80. Ishihara A, Yamashiro J, Matsumoto A, Higashibata A, Ishioka N, Shimazu T, Ohira Y (2006) Comparison of cell body size and oxidative enzyme activity in motoneurons between the cervical and lumbar segments in the rat spinal cord after spaceflight and recovery. Neurochem Res 31:411-415

81. Nagatomo F, Ishihara A, Ohira Y (2009) Effects of hindlimb unloading at early postnatal growth on cell body size in spinal motoneurons innervating soleus muscle of rats. Int J Dev Neurosci 27:21-26

82. Ishihara A, Nagatomo F, Fujino H, Kondo H, Ohira Y (2013) Decreased succinate dehydrogenase activity of gamma and alpha motoneurons in mouse spinal cords following 13 weeks of exposure to microgravity. Neurochem Res 38:2160-2167

83. Takemura A, Roy RR, Yoshihara I, Ishihara A (2017) Unloadinginduced atrophy and decreased oxidative capacity of the soleus muscle in rats are reversed by pre- and postconditioning with mild hyperbaric oxygen. Physiol Rep 5:e13353
84. Adler CH (2005) Nonmotor complications in Parkinson's disease. Mov Disord 20(Suppl 11):S23-S29

85. Dauer W, Przedborski S (2003) Parkinson's disease: mechanisms and models. Neuron 39:889-909

86. Kusuda Y, Takemura A, Nakano M, Ishihara A (2018) Mild hyperbaric oxygen inhibits the decrease of dopaminergic neurons in the substantia nigra of mice with MPTP-induced Parkinson's disease. Neurosci Res 132:58-62

87. Mudò G, Mäkelä J, Di Liberto V, Tselykh TV, Olivieri M, Piepponen P, Eriksson O, Mälkiä A, Bonomo A, Kairisalo M, Aguirre JA, Korhonen L, Belluardo N, Lindholm D (2012) Transgenic expression and activation of PGC- $1 \alpha$ protect dopaminergic neurons in the MPTP mouse model of Parkinson's disease. Cell Mol Life Sci 69:1153-1165

88. Wu Z, Puigserver P, Andersson U, Zhang C, Adelmant G, Mootha V, Troy A, Cinti S, Lowell B, Scarpulla RC, Spiegelman BM (1999) Mechanisms controlling mitochondrial biogenesis and respiration through the thermogenic coactivator PGC-1. Cell 98:115-124

89. Liang H, Ward WF (2006) PGC-1 $\alpha$ : a key regulator of energy metabolism. Adv Physiol Educ 30:145-151

90. Zadoev SA, Evdokimov VV, Rumiantsev VB, Osmolovskiǔ EO (2001) Hyperbaric oxygenation in the treatment of patients with chronic congestive prostatitis and lower fertility. Urologiia $1: 27-30$

91. Leverment J, Turner R, Bowman M, Cooke CJ (2004) Report of the use of hyperbaric oxygen therapy (HBO2) in an unusual case of secondary infertility. Undersea Hyperb Med 31:245-250

92. Van Voorhis BJ, Greensmith JE, Dokras A, Sparks AE, Simmons ST, Syrop CH (2005) Hyperbaric oxygen and ovarian follicular stimulation for in vitro fertilization: a pilot study. Fertil Steril $83: 226-228$

93. Mitrović A, Nikolić B, Dragojević S (2006) Hyperbaric oxygenation as a possible therapy of choice for infertility treatment. Bosn J Basic Med Sci 6:21-24

94. Mitrović A, Brkić P, Jovanović T (2011) The effects of hyperbaric oxygen treatment on vigility of spermatozoids: preliminary report. Acta Physiol Hung 98:85-90

95. Metelev AY, Bogdanov AB, Ivkinl EV, Mitrokhin AA, Vodneva MM, Veliev EL (2015) Hyperbaric oxygen therapy in the treatment of male infertility associated with increased sperm DNA fragmentation and reactive oxygen species in semen. Urologiia 5:74-76

96. Yoshikawa F, Netsu Y, Shimizu T, Ishihara A (2019) Mild hyperbaric oxygen improves the outcome of infertility treatment. J Reprod Med (accepted)

Publisher's Note Springer Nature remains neutral with regard to jurisdictional claims in published maps and institutional affiliations. 